Supporting Information

\title{
Synthesis of Monodisperse Pt Nanocubes and Their Enhanced Catalysis for Oxygen Reduction
}

\author{
Chao Wang, ${ }^{\dagger}$ Hideo Daimon, ${ }^{\ddagger}$ Youngmin Lee, ${ }^{\dagger}$ Jaemin Kim, $^{\dagger}$ Shouheng Sun ${ }^{*}{ }^{\dagger}$ \\ Department of Chemistry and Division of Engineering, Brown University, Providence, \\ Rhode Island 02912; Technology \& Development Division, Hitachi Maxell, Ltd. 6-20-1 \\ Kinunodai, Tsukubamirai, Ibaraki, 300-2496 Japan
}

\section{Synthesis}

The synthesis was carried out using standard airless procedures and commercially available reagents. 1-octadecene (90\%), Benzyl ether (99\%), oleylamine (>70\%), oleic acid (90\%), and iron pentacarbonyl $\left(\mathrm{Fe}(\mathrm{CO})_{5}\right)$ were purchased from Sigma Aldrich. Platinum (II) acetylacetonate was purchased from Strem Chemicals, Inc.

Synthesis of $8 \mathrm{~mm}$ Pt nanocubes. Under a nitrogen flow, $0.2 \mathrm{~g}$ of $\mathrm{Pt}(\mathrm{acac})_{2}$ was mixed with $10 \mathrm{~mL}$ 1-octadecene (ODE), $1 \mathrm{~mL}$ oleic acid and $1 \mathrm{~mL}$ oleylamine. The formed solution was slowly heated to $120^{\circ} \mathrm{C}$ in $20 \mathrm{~min}$. After $30 \mathrm{~min}$ of heating at $120^{\circ} \mathrm{C}$, under a blanket of nitrogen, one drop $(0.01 \sim 0.03$ $\mathrm{ml}$ ) of $\mathrm{Fe}(\mathrm{CO})_{5}$ solution (prepared by mixing $0.1 \mathrm{~mL} \mathrm{Fe}(\mathrm{CO})_{5}$ with $1 \mathrm{~mL} \mathrm{ODE}$ ) was added to this solution. The temperature was raised to $200^{\circ} \mathrm{C}\left(3-5^{\circ} \mathrm{C} / \mathrm{min}\right)$ and kept at this temperature for $30 \mathrm{~min}$. The solution was cooled down to room temperature. $40 \mathrm{~mL}$ of isopropanol was added and the product was separated by centrifugation (8000 rpm for $10 \mathrm{~min}$ ). The product was then dispersed in hexane.

Synthesis of $8 \mathrm{~mm}$ Pt nanoparticles without addition of Fe(CO) $)_{5} 0.2 \mathrm{~g}$ of $\mathrm{Pt}(\mathrm{acac})_{2}$ was mixed with $10 \mathrm{~mL}$ 1-octadecene (ODE), $1 \mathrm{~mL}$ oleic acid and $1 \mathrm{~mL}$ oleylamine in nitrogen atmosphere. The formed solution was slowly heated to $120^{\circ} \mathrm{C}$ in $20 \mathrm{~min}$. After $30 \mathrm{~min}$ of heating at $120^{\circ} \mathrm{C}$, the temperature was raised to $200^{\circ} \mathrm{C}\left(3-5^{\circ} \mathrm{C} / \mathrm{min}\right)$ and kept at this temperature for $30 \mathrm{~min}$. The work-up procedure was same as above.

Synthesis of 8 nm Pt nanoparticles without oleic acid. Under a nitrogen flow, 0.2 g of Pt(acac) $)_{2}$ was mixed with $10 \mathrm{~mL}$ 1-octadecene (ODE) and $1 \mathrm{~mL}$ oleylamine. The formed solution was slowly heated to $120^{\circ} \mathrm{C}$. After $30 \mathrm{~min}$, under a blanket of nitrogen, one drop $(0.01 \sim 0.03 \mathrm{ml})$ of $\mathrm{Fe}(\mathrm{CO})_{5}$ solution (prepared by mixing $0.1 \mathrm{~mL} \mathrm{Fe}(\mathrm{CO})_{5}$ with $1 \mathrm{~mL} \mathrm{ODE}$ ) was added to this solution. The temperature was raised to $200^{\circ} \mathrm{C}\left(3-5^{\circ} \mathrm{C} / \mathrm{min}\right)$ and kept at this temperature for $30 \mathrm{~min}$. The work-up procedure was same as above.

\section{Characterization}

Samples for TEM analysis were prepared by depositing one drop of diluted nanoparticle dispersion in hexane on amorphous carbon coated copper grids. Images were obtained by a Philips EM 420 (120

\footnotetext{
†rown University.

${ }^{\ddagger}$ Hitachi Maxell, Ltd.
} 
kV). HRTEM image was obtained on a JEOL 2010 TEM (200 kV). XRD patterns were obtained on a Bruker AXS D8-Advanced diffractometer with $\mathrm{Cu} \mathrm{K \alpha}$ radiation $(\lambda=1.5418 \AA)$. SEM images were obtained on a LEO 1560 scanning electron microscope. Quantitative elemental analyses were carried out with spatially resolved energy disperse X-ray spectroscopy (EDS) on the LEO 1560. Samples for EDS were prepared by depositing the nanocube dispersion on a silicon substrate and solvent was allowed to evaporate under ambient conditions. Electrochemical measurements were performed on an Electrochemical Analyzer, Model 701A, ALS/[H] CH Instrument by typical cyclic voltammetry (CV) technique. $\mathrm{Ag} / \mathrm{AgCl}$ and $\mathrm{Au}$ wire were used as reference and counter electrodes respectively.

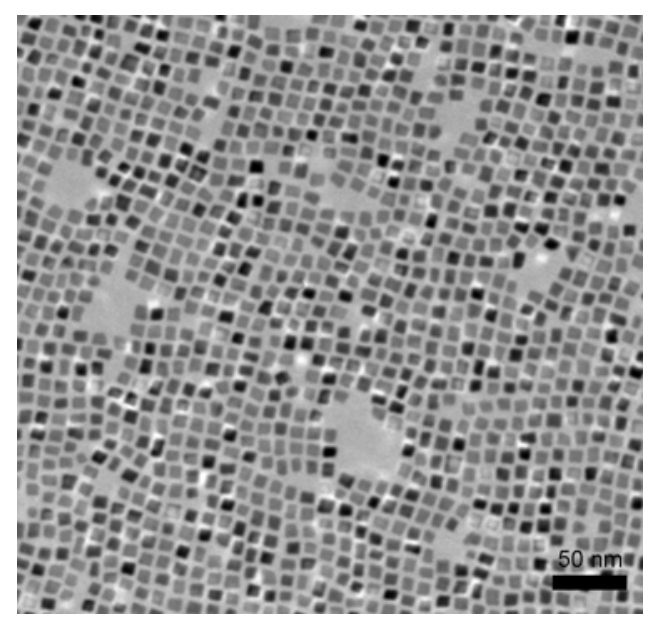

Figure S1. TEM images of the $8 \mathrm{~nm}$ Pt nanocubes.

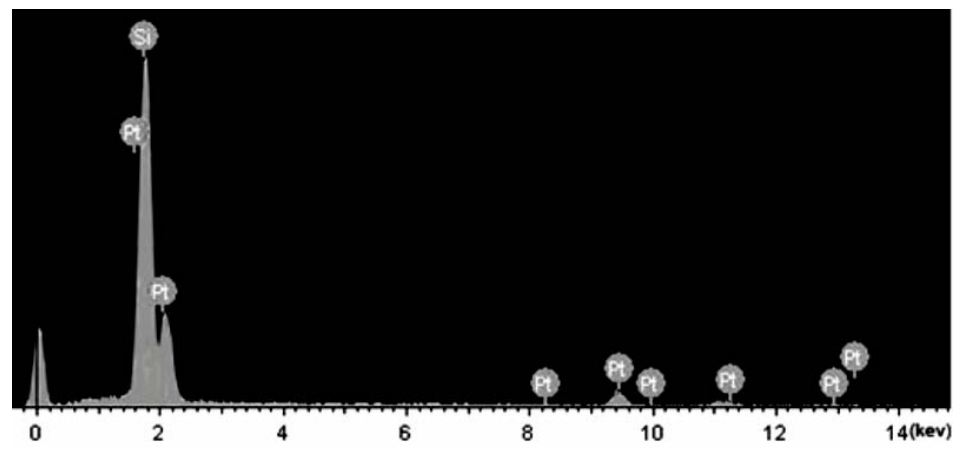

Figure S2. EDS pattern of the $8 \mathrm{~nm}$ Pt nanocubes. 


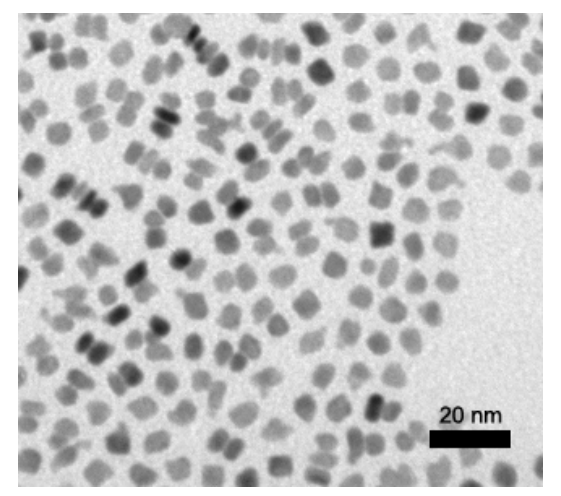

Figure S3. TEM image of the Pt nanoparticles synthesized in the absence of $\mathrm{Fe}(\mathrm{CO})_{5}$.

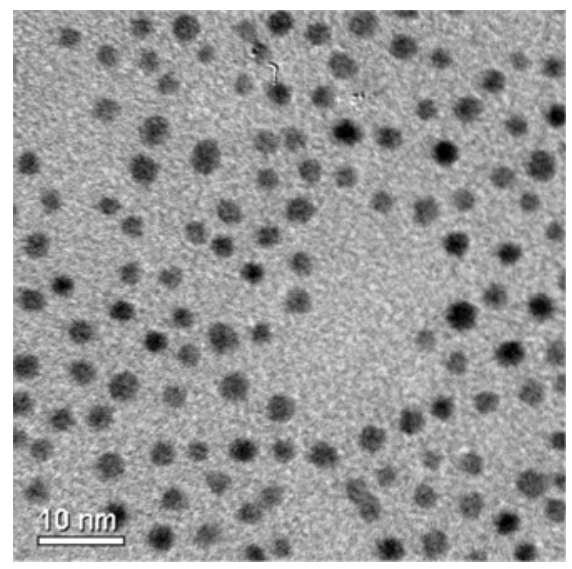

Figure S4. TEM image of the $3 \mathrm{~nm}$ Pt nanoparticles separated from the reaction mixture $10 \mathrm{~min}$ after the color of the reaction mixture changed to black ( 15 min after the injection of $\left.\mathrm{Fe}(\mathrm{CO})_{5}\right)$. The sample taken from the reaction mixture was injected right into isopropanol to make sure the morphology of the particles did not change during the separation process.

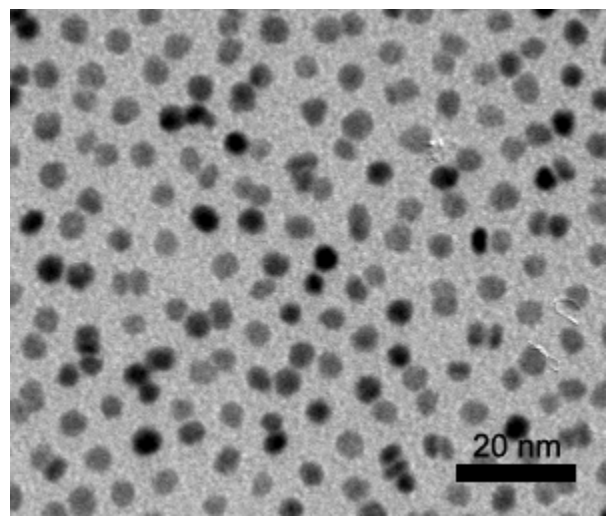

Figure S5. TEM image of the Pt nanoparticles synthesized without the addition of oleic acid in the 
reaction mixture.

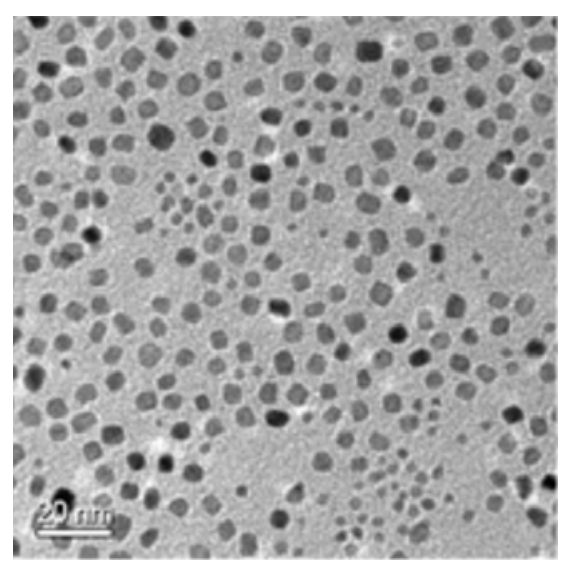

Figure S6. TEM image of the Pt nanoparticles prepared in the presence of oleic acid only. The synthesis gave low yield of Pt nanoparticles as majority of the product was precipitated out. The particles dispersed in hexane are polydispersed, but show cube-like shape.

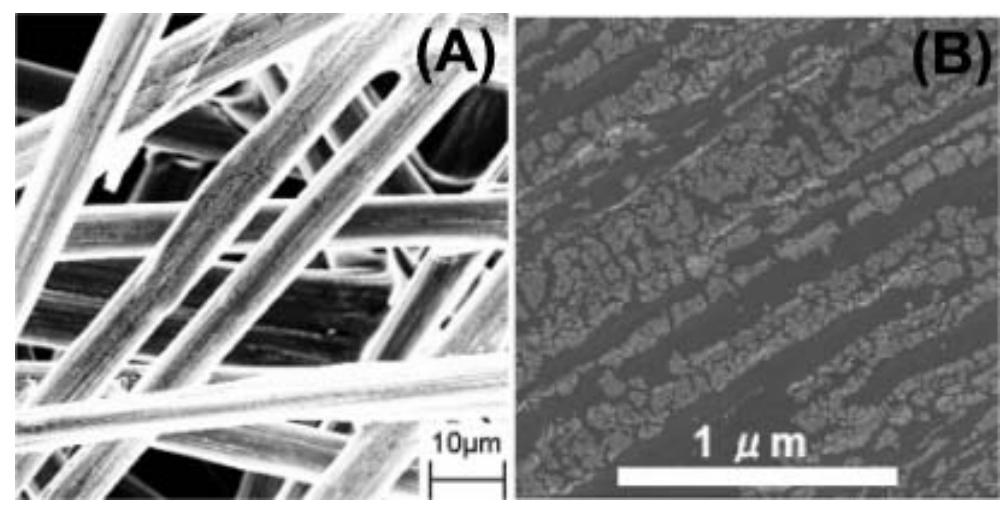

Figure S7. (A) SEM image of a typical area of the carbon paper used for electrochemical experiments and (B) HRSEM image of the $8 \mathrm{~nm}$ Pt nanocubes on one carbon fiber. 